\title{
Ocean Front Reconstruction Method Based on K-Means Algorithm Iterative Hierarchical Clustering Sound Speed Profile
}

\author{
Yuyao Liu, Wei Chen *, Yu Chen *, Wen Chen, Lina Ma and Zhou Meng
}

check for updates

Citation: Liu, Y.; Chen, W.; Chen, Y.; Chen, W.; Ma, L.; Meng, Z. Ocean Front Reconstruction Method Based on K-Means Algorithm Iterative Hierarchical Clustering Sound Speed Profile. J. Mar. Sci. Eng. 2021, 9, 1233. https://doi.org/10.3390/jmse9111233

Academic Editor: Alberto Ribotti

Received: 5 October 2021

Accepted: 3 November 2021

Published: 8 November 2021

Publisher's Note: MDPI stays neutral with regard to jurisdictional claims in published maps and institutional affiliations.

Copyright: (c) 2021 by the authors. Licensee MDPI, Basel, Switzerland. This article is an open access article distributed under the terms and conditions of the Creative Commons Attribution (CC BY) license (https:/ / creativecommons.org/licenses/by/ $4.0 /)$.
College of Meteorology and Oceanography, National University of Defense Technology, Changsha 410073, China; liuyuyao19@nudt.edu.cn (Y.L.); chenwen_hql@126.com (W.C.); mln_c7@nudt.edu.cn (L.M.); zhoumeng6806@163.com (Z.M.)

* Correspondence: kevinkobegames@126.com (W.C.); chenyu@nudt.edu.cn (Y.C.)

Abstract: As one of the most common mesoscale phenomena in the ocean, the ocean front is defined as a narrow transition zone between two water masses with obviously different properties. In this study, we proposed an ocean front reconstruction method based on the K-means algorithm iterative hierarchical clustering sound speed profile (SSP). This method constructed the frontal zone from the perspective of SSP. Meanwhile, considering that acoustic ray tracing is a very sensitive tool for detecting the location of ocean fronts because of the strong dependence of the transmission loss (TL) on SSP structure, this paper verified the feasibility of the method from the perspective of the TL calculation. Compared with other existing methods, this method has the key step of iterative hierarchical clustering according to the accuracy of clustering results. The results of iterative hierarchical clustering of the SSP can reconstruct the ocean front. Using this method, we reconstructed the ocean front in the Gulf Stream-related sea area and obtained the three-dimensional structure of the Gulf Stream front (GSF). The three-dimensional structure was divided into seven layers in the depth range of 0-1000 $\mathrm{m}$. Iterative hierarchical clustering SSP by K-means algorithm provides a new method for judging the frontal zone and reconstructing the geometric model of the ocean front in different depth ranges.

Keywords: ocean front; K-means algorithm; reconstruction; iterative hierarchical clustering; transmission loss

\section{Introduction}

As one of the most important phenomena in ocean dynamics, the ocean front is defined as a narrow transition zone between two or more water masses with different properties [1] The frontal zone is a convergence zone area, which has very strong vertical movement. The exchange of momentum, heat, and water vapor in the frontal zone is very active [2], and the position and strength of the frontal zone vary with time or season [3], so ocean fronts have become a hot topic of physical oceanography in recent years. For the detection of the ocean front, the dynamic method or the gradient judgment method of hydrological elements including temperature can be used $[4,5]$, in which a critical value should be given first. If the calculated horizontal temperature gradient is greater than the critical value, it is considered that there is an ocean front [6].

The impact of the ocean front on acoustic transmission loss (TL) can not be ignored [7]. Research has shown that the maximum difference of the TL between the existing front and none is about $20 \mathrm{~dB}$ [8], which greatly has an impact on the detection performance of the sonar equipment. Therefore, it is critical to accurately construct the three-dimensional geometric structure of the frontal zone, which helps study the influence of acoustic propagation. As an important factor affecting the characteristics of underwater acoustic propagation, the sound speed profile (SSP) reflects the vertical distribution structure of the seawater 
sound speed [9]. The front will significantly affect the spatial distribution characteristics of the SSP [10], which can be employed to determine the frontal zone. Because of the strong dependence of the TL on SSP structure, acoustic ray tracing is a very sensitive tool for detecting the location of ocean fronts, which can be used for studying the ocean front and its acoustic effects.

It is a new method to detect the frontal zone by using cluster analysis of the SSP. Cluster analysis refers to the analysis process of grouping a collection of physical or abstract objects into multiple classes composed of similar objects. It is an important human behavior. The goal of cluster analysis is to collect data to classify on the basis of similarity. Clustering comes from many fields, including mathematics, computer science, statistics, biology, and economics. In different application fields, many clustering techniques have been developed. These technical methods are used to describe data, measure the similarity between different data sources, and classify data sources into different clusters. The principle of cluster analysis is that the data in the same category have great similarities, and the data between different categories are very different. Due to the obvious differences in the structure of the SSP in the sea area where the ocean front exists, it is a reliable method to perform the category recognition of SSP to detect the frontal zone by using cluster analysis of the SSP. The classification research of the SSP by cluster analysis was first used in the 21st century. Mandelberg et al. [11] used the hierarchical clustering method to classify the SSP of the North Atlantic and the Northeast Pacific. Abiva et al. [12] used principal component analysis (PCA) and self-organizing map (SOM) to automatically cluster the SSP, which was applicable in terms of the sea area of the Strait of Gibraltar. In addition, Dubberley and Zingerelli [13] applied fuzzy clustering to oceanographic parameters related to acoustics and divided them into multiple categories, which proved the practicability of the method. As far as the current research is concerned, many studies have applied cluster analysis and other related methods to the classification of sound speed profiles. However, there are few studies on the clustering of sound speed profiles under the mesoscale ocean phenomenon such as the ocean front in specific sea areas. Chen et al. [14] used the K-means algorithm for the cluster analysis of sound speed profiles of the whole sea depth in the area of the Kuroshio extension front, extracted three types of characteristic sound speed profiles, and established the Kuroshio extension front (KEF) sound speed characteristic model. Liu et al. [15] used the fuzzy C-means (FCM) algorithm to cluster the surface sound speed of the Kuroshio extension area and determined the surface position of the frontal zone and its information. Considering the changing characteristics of the ocean front in different depth ranges, it is necessary to cluster sound speed profiles of the ocean front in different sea layers to reconstruct the geometric model of the ocean front, but there are few studies in this regard. Liu et al. [16] divided the set of sound speed profiles of the Luzon Strait into three layers and clustered the sound speed profiles of each layer to reconstruct the three-layer structure of the Kuroshio intrusion front (KIF). Although it is a layered reconstruction method for the ocean front, the number of layers is fixed at the beginning, that is, the layering principle is not fully considered, so the results are completely related to the initial value of layering, and there is no means to optimize the layering through iteration.

In this paper, we select the ocean front in the Gulf Stream area as the research object, cluster the sound speed profiles in different depth ranges in the study area by K-means algorithm, and verify the accuracy of the clustering results in different depth ranges by calculating the TL. There is a key step of iterative optimization and stratification based on the accuracy of the K-means clustering results. Finally, we successfully construct the three-dimensional structure of the Gulf Stream front (GSF) for the first time.

Section 1 of this paper is the introduction. In Section 2 of this paper, the data and methods are introduced, including the physical oceanography and data introduction, the description of the K-means algorithm and its application, the BELLHOP ray model and its application, and the technical route of the research process. Section 3 of this paper is results and discussion, and we divide this section into five parts, including the selection 
of the number of layers of clustering, the classification and recognition of sound speed profiles based on K-means, the verification of the accuracy of clustering results based on calculating the TL, iterative layered processing and verification, and the construction of the three-dimensional geometric structure of the GSF. Section 4 of this paper is a summary and conclusion, and we summarize the whole research process and give relevant conclusions.

\section{Data and Methods}

\subsection{Physical Oceanography and Data Introduction}

The Gulf Stream is the most powerful and influential warm stream in the world [17,18]. Due to the differences in intensity and position of the Gulf Stream in different seasons, the range and position of the GSF also show obvious seasonal differences. In this paper, our study area was selected within the range shown in Figure 1a. We enlarge Figure 1a and get Figure $1 \mathrm{~b}$ to show the surface sound speed distribution of the study area (the scope of the study area is $38^{\circ}-40^{\circ} \mathrm{W}, 50.6^{\circ}-51.6^{\circ} \mathrm{N}$ ). As can be seen in Figure $1 \mathrm{~b}$, due to the existence of the GSF, the study area is divided into three water masses with different properties. They are a high sound speed (high temperature and salinity) water mass, which is located in the southern part of the frontal zone; low sound speed (low temperature and salinity) water mass, which is located in the northern part of the frontal zone; and a transitional water mass, which is located in the frontal zone.

(a)

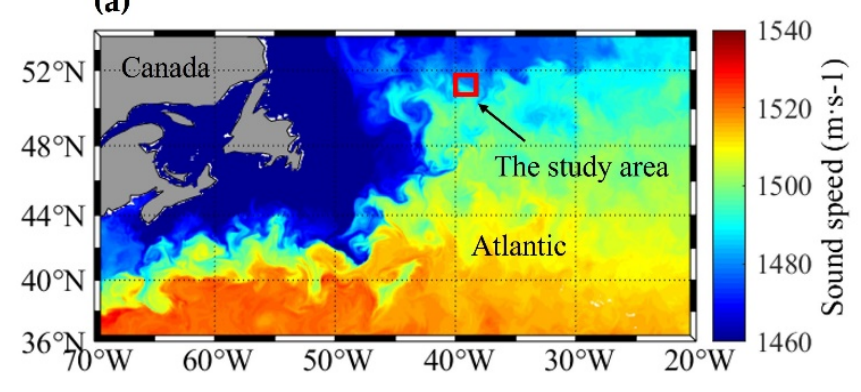

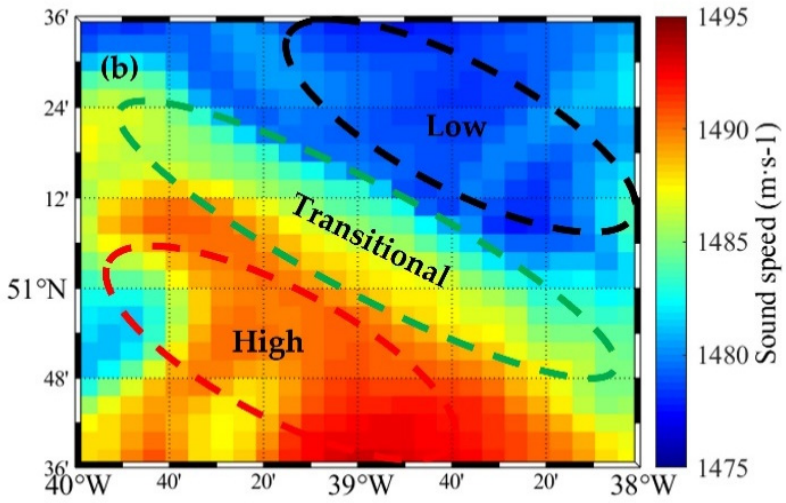

Figure 1. (a) The surface sound speed of parts of the North Atlantic and the location of the study area (the scope of the study area is $38^{\circ}-40^{\circ} \mathrm{W}, 50.6^{\circ}-51.6^{\circ} \mathrm{N}$ ); (b) The sea surface sound speed distribution of the study area on 1 January 2019 . Due to the existence of the GSF, the study area is divided into three water masses with different properties. They are high sound speed (high temperature and salinity) water mass, which is located in the southern part of the frontal zone; low sound speed (low temperature and salinity) water mass, which is located in the northern part of the frontal zone; transitional water mass, which is located in the frontal zone.

HYCOM (the Hybrid Ocean Model) $[19,20]$ was used to output daily average temperature, salinity, and depth (pressure) data, which were gridded reanalyzed, and the data type was NetCDF (Network Common Data Format). Considering that the ocean front is obviously strong in winter, we used the daily average data on 1 January to detect the frontal zone more clearly. The data have a horizontal resolution of $0.08^{\circ}$ in longitude and $0.04^{\circ}$ in latitude and the vertical stratification is 40 (The stratification is uneven). The speed of sound in seawater is a function of temperature, salinity, and depth (pressure), and the relationship between them can be expressed by a simplified empirical formula of sound speed:

$$
C=1449.22+\Delta C_{t}+\Delta C_{S}+\Delta C_{P}+\Delta C_{S t P}
$$

where $C$ refers to sound speed, $\Delta C_{t}, \Delta C_{S}, \Delta C_{P}, \Delta C_{S t P}$ are sound speed disturbance caused by temperature, salinity, pressure and their combined influence respectively, and their expressions are as follow:

$$
\Delta C_{t}=4.6223 t-5.4585(10)^{-2} t^{2}+2.822(10)^{-4} t^{3}-5.07(10)^{-7} t^{4},
$$




$$
\begin{gathered}
\Delta C_{S}=1.391(S-35)-7.8(10)^{-2}(S-35)^{2}, \\
\Delta C_{p}=1.60518(10)^{-1} P+1.0279(10)^{-5} P^{2}+3.451(10)^{-9} P^{3}-3.503(10)^{-12} P^{4}, \\
\Delta C_{S t P}=(S-35)\left[-1.197(10)^{-3} t+2.61(10)^{4} P-1.96(10)^{-1} P^{2}-2.09(10)^{-6} P t\right] \\
+P\left[-2.796(10)^{4} t+1.3302(10)^{-5} t^{2}-6.644(10)^{-8} t^{3}\right] \\
+P^{2}\left[-2.391(10)^{-1} t+9.286(10)^{-10} t^{2}\right]-1.745(10)^{-10} P^{3} t
\end{gathered}
$$

where $t$ is the temperature, $P$ is the pressure in standard atmospheric pressure, and $S$ is the salinity. This empirical equation was proposed by Wilson in 1960 [21]. The formula has a wide range of applications in the global ocean, and the error is basically controlled at $1 \mathrm{~m} / \mathrm{s}$. Using the sound speed empirical formula, $n$ sound speed profiles in the study area are obtained, and all sound speed profiles form the sound speed matrix $T$ :

$$
T=\left[\begin{array}{cccc}
T_{11} & T_{12} & \ldots & T_{1 m} \\
T_{21} & T_{22} & \ldots & T_{2 m} \\
\ldots & \ldots & \ldots & \ldots \\
T_{n 1} & T_{n 2} & \ldots & T_{n m}
\end{array}\right] .
$$

The sound speed matrix $T$ is $n \times m$ matrix, where $n$ is the number of sound speed profiles (each row of the matrix represents an SSP), and $m$ is the number of layers of sound speed profiles of the whole sea depth.

\subsection{K-Means Algorithm and Its Application}

Fuzzy cluster analysis refers to constructing a fuzzy matrix according to the properties of the research object itself and determining the cluster relationship according to certain membership, aiming to perform clustering objectively and accurately [22]. In this paper, as a kind of fuzzy clustering method, the K-means algorithm was used to cluster $n$ sound speed profiles in the study area. K-means algorithm is an iterative clustering analysis method. It divides the data into $K$ groups in advance, randomly selects $K$ objects as the initial clustering center, then calculates the distance (in this paper, the distance between the objects and the clustering centers indicates the degree of similarity between the objects and the clustering centers: the smaller the distance, the higher the degree of similarity; on the contrary, the larger the distance, the lower the degree of similarity. Euclidean distance was used for calculation, and its expression is given below) between each object and each initial clustering center to assign each object to the nearest clustering center. The clustering center and the objects assigned to them represent a cluster [23]. Each time a sample was allocated, the clustering center was recalculated according to the existing objects in the cluster. This process was repeated until a certain termination condition (such as minimizing the square error) was met. The scope of the study area in this manuscript is $38^{\circ}-40^{\circ} \mathrm{W}$, $50.6^{\circ}-51.6^{\circ} \mathrm{N}$, and the data we used have a latitude horizontal resolution of $0.04^{\circ}$ and a longitude horizontal resolution of $0.08^{\circ}$, so there are $26^{*} 26=676$ sound speed profiles in the study area. K-means algorithm divides the 676 sound speed profiles in the study area into $K$ groups (the classification number $K$ is artificially defined. Considering that the GSF divides the study area into three water masses, namely, water masses with different properties on both sides of the frontal zone and transitional water mass between them, $K$ is taken as 3), and the clustering center of each group was found by minimizing the square error. The square error can be expressed as:

$$
E=\sum_{q=1}^{3} \sum_{x \in C_{q}}\left\|x-\mu_{q}\right\|^{2}
$$


where $x$ is each SSP, $C_{q}$ is the cluster group $(q=1,2,3), \mu_{q}$ is the mean vector of $C_{q}$, which is the clustering center, also known as the center of mass, and its expression is:

$$
\mu_{q}=\frac{1}{\left|C_{q}\right|} \sum_{x \in C_{q}} x
$$

In Equation (7), $\left\|x-\mu_{q}\right\|$ is the Euclidean distance between $x$ and $\mu_{q}$, and its expression is:

$$
|| x-\mu_{q} \|=\sqrt{\left(x-\mu_{q}\right)^{2}} .
$$

The steps of clustering of sound speed profiles using the K-means algorithm in this paper are as follows:

(1) Determining the number of layers and the depth range of each layer. After calculating the sound speed matrix $T$, according to the actual influence depth of the GSF (in this paper, the actual depth of influence of the GSF is $1000 \mathrm{~m}$ (Section 3.1)), we divide the depth into five layers evenly as our initial stratification, and the depth range of each layer is $200 \mathrm{~m}$. A total of 676 sound speed profiles of each layer are clustered via the K-means algorithm.

(2) Initializing the sound speed matrix $T$ of each layer with a number between 0 and 1. This step can be completed through translation-standard deviation transformation and translation-range transformation.

The expression of translation-standard deviation transformation is as follows:

$$
T_{i j}^{\prime}=\frac{T_{i j}-\bar{T}_{j}}{s_{j}},
$$

where $i=1,2, \ldots, 676, j$ is the distribution number of the selected collection sampling points of the SSP of each layer in depth. For example, for the SSP of 0-200 m, there are 10 sampling points in the depth range of $0-200 \mathrm{~m}, j=1,2, \ldots, 10$. The expressions of $\bar{T}_{j}$ and $s_{j}$ are as follow:

$$
\bar{T}_{j}=\frac{1}{676} \sum_{i=1}^{676} T_{i j}, s_{j}=\left[\frac{1}{676} \sum_{i=1}^{676}\left(T_{i j}-\bar{T}_{j}\right)^{2}\right]^{\frac{1}{2}} .
$$

The expression of translation-range transformation is as follows:

$$
T_{i j}^{\prime \prime}=\frac{T_{i j}^{\prime}-\min _{1 \leq i \leq 676}\left\{T_{i j}^{\prime}\right\}}{\max _{1 \leq i \leq 676}\left\{T_{i j}^{\prime}\right\}-\min _{1 \leq i \leq 676}\left\{T_{i j}^{\prime}\right\}} .
$$

After transformation, all $T_{i j}^{\prime \prime} \in[0,1]$ of the sound speed matrices can be obtained. The initialized matrix is a membership matrix $T^{\prime \prime}$.

(3) In the matrix $T^{\prime \prime}$, three sound speed profiles are randomly selected as the initial three clustering centers.

(4) The distance from each SSP to the clustering center is calculated, and the first clustering is carried out according to the principle of minimizing the square error to obtain the first clustering center:

$$
\mu_{q}=\frac{1}{\left|C_{q}\right|} \sum_{T_{i}^{\prime \prime} \in C_{q}} T_{i}^{\prime \prime}
$$

where $C_{q}$ is the cluster group $(q=1,2,3), T_{i}^{\prime \prime}$ is the row vector of the membership matrix $T^{\prime \prime}(i=1,2, \ldots, 676)$, that is the SSP after initialization. 
(5) After the first clustering of all sound speed profiles, the clustering center changes. Repeat step (4) to calculate each clustering center again until the square error is the smallest:

$$
E=\sum_{q=1}^{3} \sum_{T_{i}^{\prime \prime} \in C_{q}}\left\|T_{i}^{\prime \prime}-\mu_{q}\right\|^{2},
$$

that is, given a certain $\delta$, make $E(v+1)-E(v)<\delta$ (in this paper, $\delta=10^{-5}$ is the default value), then stop the iteration (the number of iterations is $v$ ), and complete the clustering of the sound speed profiles in this layer.

(6) Repeat steps (2) to (5) and use the K-means algorithm to cluster the sound speed profiles of other layers.

Through the above steps, we completed the clustering of the sound speed profiles under the initial stratification (five layers) by using the K-means algorithm. The result of the clustering is that the 676 sound speed profiles of each layer are divided into three groups. Each group represents a kind of water mass, and we can detect the frontal zone based on the clustering results.

\subsection{BELLHOP Ray Model and Its Application}

We used the BELLHOP ray model to calculate the TL, which can verify the accuracy of the clustering results in different layers. BELLHOP ray model is a toolbox for underwater sound field calculation [24]. Based on the ray theory, the sound field in a horizontal non-uniform environment is calculated by the Gaussian beam tracking method [25]. By adjusting the parameters of the environment file, the model can calculate the sound field and obtain the corresponding sound line information, multi-path information, and so on. Compared with the normal mode model or parabolic equation model, the ray model can clearly describe the change of sound energy in the process of propagation [26], which is more suitable for the ocean front environment in this paper. Because the TL varies greatly when passing through the frontal zone (including the size, intensity, and location of the convergence area) $[27,28]$, it is more reliable to judge the starting position of the frontal zone by comparing the TL of the existing ocean front and none. The BELLHOP ray model was used to calculate the TL to verify the accuracy of clustering results of the SSP of each layer in judging the starting position of the frontal zone. The specific steps are as follows:

(1) Sound speed sections with different longitude in the study area are selected. Take the actual sound speed section as the existing ocean front environment (there are 26 sound speed profiles of each longitude section):

$$
T_{\text {exist }}=\left[\begin{array}{cccc}
T_{11} & T_{12} & \ldots & T_{1 j} \\
T_{21} & T_{22} & \ldots & T_{2 j} \\
\ldots & \ldots & \ldots & \ldots \\
T_{26,1} & T_{26,2} & \ldots & T_{26, j}
\end{array}\right]
$$

( $j$ is the distribution number of the selected collection sampling points of the SSP of each layer in depth. For example, for the SSP of 0-200 m, there are 10 sampling points in the depth range of $0-200 \mathrm{~m}, j=1,2, \ldots, 10)$.

The distance-independent environment configured using the first SSP is regarded as an environment without an ocean front (the dimension of $T_{\text {without }}$ is the same as $T_{\text {exist }}$ ):

$$
T_{\text {without }}=\left[\begin{array}{cccc}
T_{11} & T_{12} & \ldots & T_{1 j} \\
T_{11} & T_{12} & \ldots & T_{1 j} \\
\ldots & \ldots & \ldots & \ldots \\
T_{11} & T_{12} & \ldots & T_{1 j}
\end{array}\right]
$$

The above two environments are input into the BELLHOP. On this basis, the TL between existing the frontal zone $\left(T L_{\text {exist }}\right)$ and none $\left(T L_{\text {without }}\right)$ are calculated and compared by setting sound sources with different depths and propagation directions (the sound 
source depth is located in the middle depth of each layer. The receiving depth is consistent with the sound source depth, and the TL we got corresponds to the value of the receiving depth. The setting is the same for all layers).

(2) The five-point moving average method is used to process the TL. For the determined $T L_{d i f f}$, if

$$
T L_{\text {diff }} \leq\left|T L_{\text {exist }}-T L_{\text {without }}\right|,
$$

then the corresponding position $R_{\text {exist }}$ is regarded as the starting point of the frontal zone (in the paper, the critical value $T L_{\text {diff }}$ is $0.2 \mathrm{~dB}$, that is, under the same conditions, when the difference of the TL between with and without the ocean front exceeds $0.2 \mathrm{~dB}$, it is considered that a frontal zone appears at this position, and the corresponding position $R_{\text {exist }}$ is regarded as the actual starting position of the frontal zone).

Under the same conditions, the starting position of the frontal zone under the section obtained by the K-means algorithm is $R_{K-\text { means }}$, for the certain error standard $R_{\text {error }}$, if

$$
R_{\text {error }} \geq\left|R_{\text {exist }}-R_{K-\text { means }}\right| \text {, }
$$

it is considered that the clustering results obtained by using K-means are accurate in this layer (in this paper, the error standard $R_{\text {error }}$ is twice the distance between the two sound speed profiles, which is $11.2 \mathrm{~km}$ ).

(3) Iterative optimization of stratification. If the error of the original hierarchical clustering result is greater than the error standard, that is

$$
R_{\text {error }}<\left|R_{\text {exist }}-R_{K-\text { means }}\right|,
$$

then the layer is divided into two layers evenly according to the depth range of this layer, and each layer is re-clustered according to the steps of the hierarchical clustering of sound speed profiles via K-means. Next, use the same method to verify the accuracy of the clustering results until all the hierarchical clustering results meet the error standard range for the judgment of the starting point of the frontal zone. This is an iterative process, which is completed to realize the iterative hierarchical clustering of the SSP, and all the results of the iterative hierarchical clustering can meet the allowable range of error.

\subsection{Introduction of Technical Route}

The whole research process is summarized, and the technical route is given as follows (Figure 2). First of all, we used the sound speed empirical formula to fit the temperature, salinity, and depth (pressure) data in the study area and obtain the sound speed matrix. Then, the K-means algorithm was used to cluster sound speed profiles in the study area to detect the frontal zone. In order to verify the validity of the clustering results, we used the BELLHOP ray model to calculate and compare the TL between the existing front environment and none and use the calculated starting position of the frontal zone as the criterion. If the error of the clustering results was less than the given error range, we considered the clustering results obtained by the K-means algorithm at this layer to be accurate. If the error is larger than the given error range (twice of the distance between the two sound speed profiles $(11.2 \mathrm{~km})$ ), we need to divide this layer into two layers evenly to re-cluster the sound speed profiles of each layer, and then verify the results through the TL. Until all the iterative hierarchical clustering results meet the error standard range for the judgment of the starting point of the frontal zone, the verification process is completed. The iterative process was completed to realize the iterative hierarchical clustering of the sound speed profiles, and all the results of the iterative hierarchical clustering can meet the allowable range of error. Finally, we used the results of iterative hierarchical clustering of sound speed profiles to reconstruct the structure of the ocean front. 


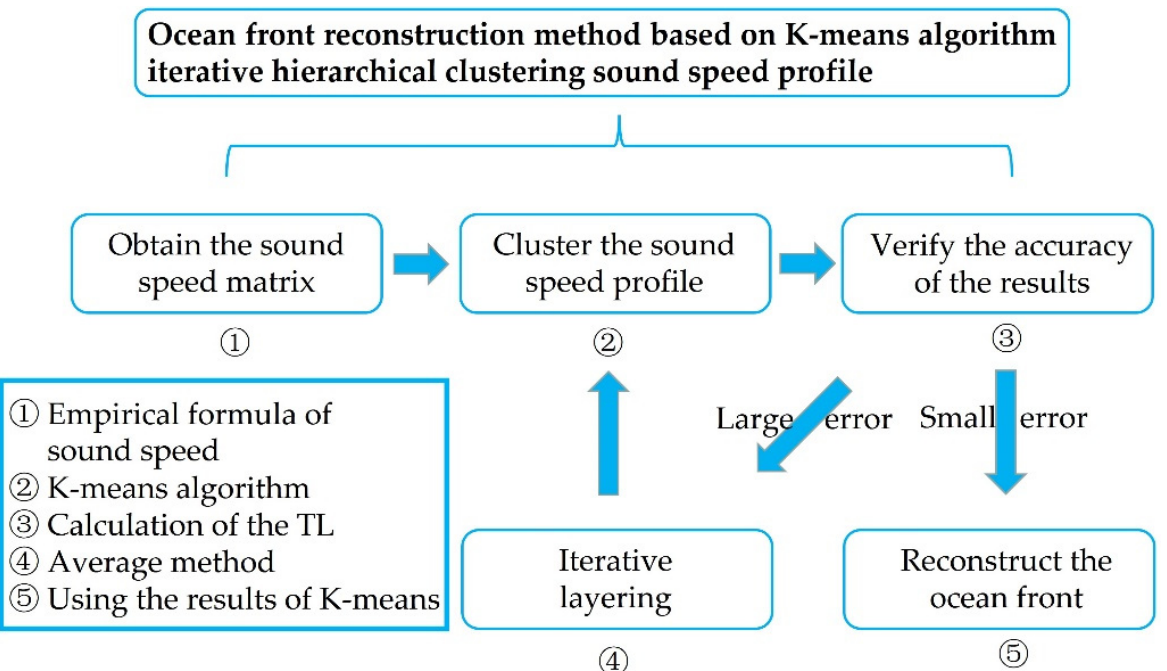

Figure 2. The technical route of the research process.

\section{Results and Discussion}

In this section, we cluster sound speed profiles with the K-means algorithm to obtain the position and range of the frontal zone of the GSF. At the same time, we verify the accuracy of clustering results based on the calculation of the TL. For larger errors in Kmeans results, we completed iterative hierarchical processing and verification. Finally, we use the results of iterative hierarchical clustering of sound speed profiles through the K-means algorithm to reconstruct the structure of the GSF.

\subsection{Selection of the Number of Layers of Clustering}

We selected a typical sound speed section at $39^{\circ} \mathrm{W}$ (the latitude range is $50.6^{\circ}-51.6^{\circ} \mathrm{N}$ ) and point $\mathrm{A}\left(39^{\circ} \mathrm{W}, 51.6^{\circ} \mathrm{N}\right), \mathrm{B}\left(39^{\circ} \mathrm{W}, 51.1^{\circ} \mathrm{N}\right)$ and $\mathrm{C}\left(39^{\circ} \mathrm{W}, 50.6^{\circ} \mathrm{N}\right)$ in the study area to obtain the sound speed distribution of the section (Figure $3 \mathrm{a}$ ) and the sound speed profiles at point A, B, and C (Figure 3b):
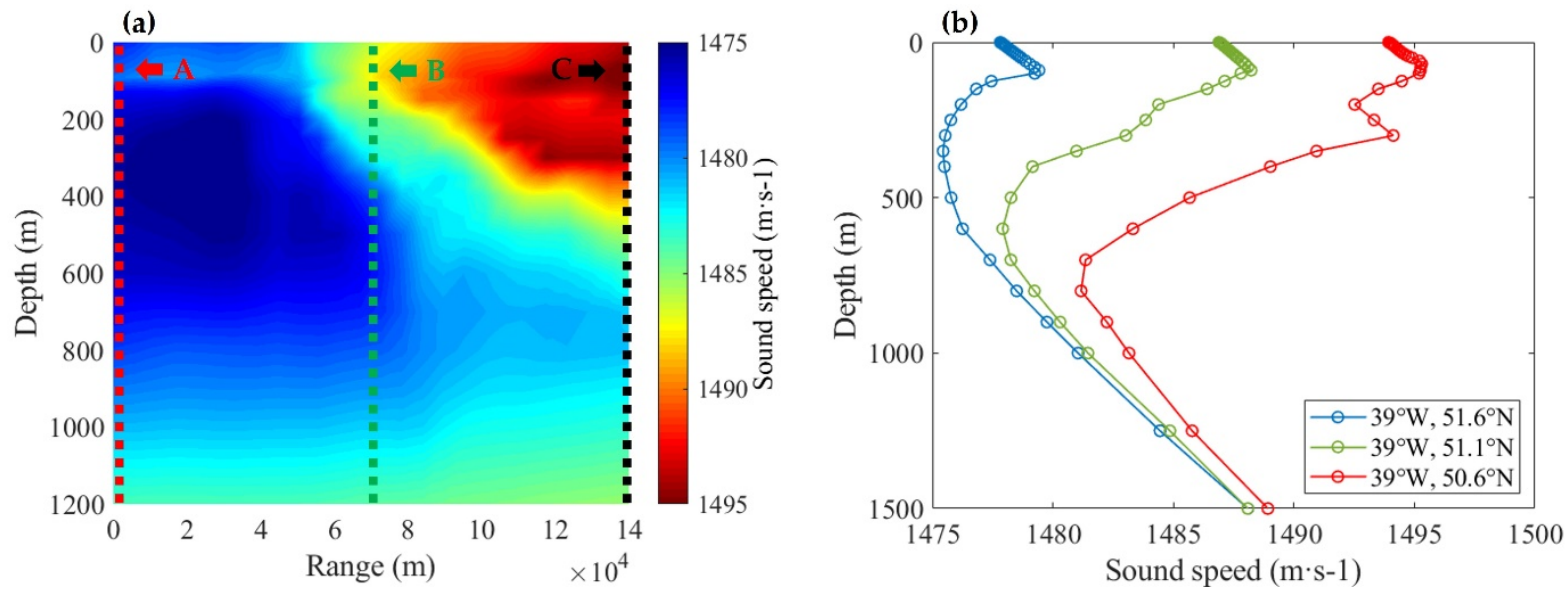

Figure 3. (a) The sound speed section at $39^{\circ} \mathrm{W}(0-1000 \mathrm{~m})$; (b) the sound speed profiles of point $\mathrm{A}\left(39^{\circ} \mathrm{W}, 51.6^{\circ} \mathrm{N}\right)$, $\mathrm{B}\left(39^{\circ} \mathrm{W}, 51.1^{\circ} \mathrm{N}\right)$, and $\mathrm{C}\left(39^{\circ} \mathrm{W}, 50.6^{\circ} \mathrm{N}\right)(0-1500 \mathrm{~m})$. Point A is located on the leftmost side, point $\mathrm{B}$ is located in the middle, and point $\mathrm{C}$ is located on the rightmost side.

Observing the sound speed section at $39^{\circ} \mathrm{W}$ and the sound speed profiles of these three points, we can see that the sound speed distribution belongs to several depth ranges. The depth of the influence of the GSF is about $1000 \mathrm{~m}$ (the horizontal distribution of sound speed hardly changes at a depth of $1000 \mathrm{~m}$, so our research sea depth is $0-1000 \mathrm{~m}$ ). The first depth range is $0-200 \mathrm{~m}$, where the sound speed varies greatly at different positions at 
the same depth. In terms of the same positions, the vertical layering in this depth range is denser, and the internal sound speed gradient reverses. The second depth range is about 200-400 m, where the sound speed decreases with depth in a relatively smooth manner (but point $C$ has a positive and negative change in the gradient of the sound speed). Meanwhile, the vertical stratification gradually becomes sparse. The third range is at about $400-600 \mathrm{~m}$ depth, where there is the SOFAR axis (minimum speed of sound) at point A covered in this range. At about $600-800 \mathrm{~m}$ depth, there are SOFAR axes at points B and C covered in this range. The last range is at $800-1000 \mathrm{~m}$. As the depth increases, the sound speed also increases in this range. The influence of the ocean front below $1000 \mathrm{~m}$ becomes very small and we will not consider it.

Based on the above analysis, we divided the depth range of the study area into five layers, namely 0-200 m, 200-400 m, 400-600 m, 600-800 m, and 800-1000 m, each layer is $200 \mathrm{~m}$ deep, corresponding to five different depth ranges. According to the above initial stratification results, we used the K-means algorithm to cluster the sound speed profiles of each layer, respectively.

\subsection{Classification and Recognition of Sound Speed Profiles Based on K-Means}

We used the K-means algorithm to classify and identify the sound speed profiles of the above five layers and obtain the following clustering results (Figure 4). We found that each layer has three types of sound speed profiles, the blue points represent the north water mass of the frontal zone, the red points represent the south water mass of the frontal zone, and the green points represent the frontal transition water mass. The first layer is $0-200 \mathrm{~m}$ (Figure 4a), the direction of the frontal zone is northwest-southeast, and it is wider in the west, which is very similar to Figure $1 \mathrm{~b}$ about the detecting result of the frontal zone. The second layer is $200-400 \mathrm{~m}$ (Figure $4 \mathrm{~b}$ ), compared with the first layer, the frontal zone is wider in the west, and the width of the frontal zone at $39^{\circ} 30^{\prime} \mathrm{W}$ section reaches $67.2 \mathrm{~km}$. The third and fourth layers (400-600 $\mathrm{m}$ and 600-800 m) are different from the second layer, the frontal zone in the west narrows suddenly and moves south. Instead, the eastern frontal zone is wider than the previous layer. The last layer is $800-1000 \mathrm{~m}$, compared with the $600-800 \mathrm{~m}$, the frontal zone is narrower in the east. The narrowest part of the whole frontal zone in this layer appears in the middle of the study area, only $11.2 \mathrm{~km}$.

According to the above results, we can find that the position, width, and range of the GSF are different at layers, which further confirms the irregular variation of the structure of the frontal zone with depth. Taking the experiment on the $39^{\circ} \mathrm{W}$ characteristic section as an example, the widths of the frontal zone at different layers are $22.4 \mathrm{~km}, 33.6 \mathrm{~km}, 11.2 \mathrm{~km}$, $11.2 \mathrm{~km}, 11.2 \mathrm{~km}$, respectively.

\subsection{Verify the Accuracy of Clustering Results Based on the Calculation of the TL}

We used the BELLHOP ray model to calculate the TL, which is used to verify the accuracy of the clustering results in different layers. We selected sound speed sections at different longitudes in the study area. On this basis, by setting sound sources of different depths, we calculated and compared the TL in the presence and absence of the frontal zone. Next, we set the position with a large difference in the TL as the starting point of the frontal zone (in this paper, this standard is set to $0.2 \mathrm{~dB}$, that is, under the same conditions, when the difference of the TL between the existing the ocean front and the none exceeds $0.2 \mathrm{~dB}$, it was considered that a frontal zone appears at this position, and it was regarded as the actual starting position of the frontal zone). By comparing the differences of the starting points, we can verify the accuracy of the results of K-means of each layer. The relevant parameters set in the process of calculating TL are as follows: the sound source frequency is $50 \mathrm{~Hz}$, the receiving depth is consistent with the source depth, the glancing angle is $-20-20^{\circ}$, the seabed sound speed is $1600 \mathrm{~m} / \mathrm{s}$, the density is $1.8 \mathrm{~g} / \mathrm{cm}^{3}$, and the sound absorption coefficient of the seabed is $0.8 \mathrm{~dB} / \lambda$. 

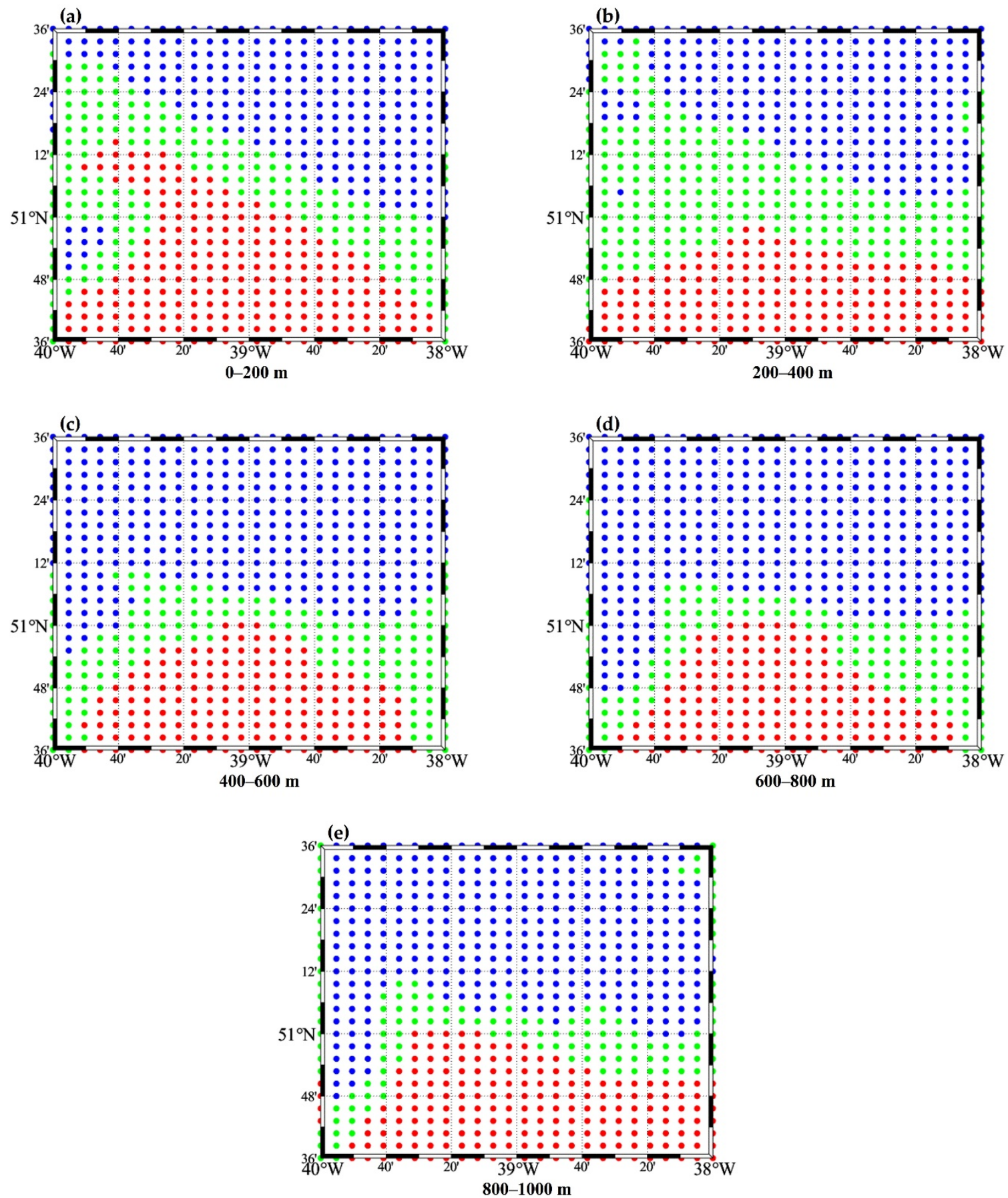

Figure 4. The results of clustering the sound speed profiles of the study sea area via K-means (the blue points represent the north water mass of the frontal zone, the red points represent the south water mass of the frontal zone, and the green points represent the frontal transition water mass): (a) 0-200 m; (b) 200-400 m; (c) 400-600 m; (d) 600-800 m; (e) 800-1000 m.

Three sound speed sections $\left(39.5^{\circ} \mathrm{W}, 39^{\circ} \mathrm{W}\right.$, and $\left.38.5^{\circ} \mathrm{W}\right)$ were selected to calculate the TL (each sound speed section has two directions, $50.6^{\circ}-51.6^{\circ} \mathrm{N}$ and $51.6^{\circ}-50.6^{\circ} \mathrm{N}$ ). When the sound speed section is $39.5^{\circ} \mathrm{W}$, the comparison of the TL between the existing frontal zone and none at 0-200 $\mathrm{m}$ (Figure 5a) and 200-400 $\mathrm{m}$ (Figure 5b) are as follows. We calculated the TL of $39.5^{\circ} \mathrm{W}$ section in the layer of $0-200 \mathrm{~m}$ (the propagation direction is $\left.50.6^{\circ}-51.6^{\circ} \mathrm{N}\right)$. The position when the difference exceeds $0.2 \mathrm{~dB}$ is used as the criterion for judging the starting point of the frontal zone, and this value is $17.9 \mathrm{~km}$, while the result of K-means under this condition is $50.4 \mathrm{~km}$ (Figure $4 \mathrm{a}$ ), which is more than twice the distance between the two sound speed profiles $(11.2 \mathrm{~km})$. It is necessary to divide the $0-200 \mathrm{~m}$ into 
0-100 $\mathrm{m}$ and 100-200 m, use the K-means algorithm to cluster the SSP, and then verify the accuracy of the new results. In Figure $5 b$, using the same method, the value is $77.2 \mathrm{~km}$, while the result of K-means under this condition is $39.2 \mathrm{~km}$ (Figure $4 \mathrm{~b}$ ), which is also more than twice the distance between the two sound speed profiles. It is also necessary to divide the 200-400 m into 200-300 m and 300-400 m, use the K-means algorithm to cluster the SSP, and then verify the accuracy of the results of K-means.
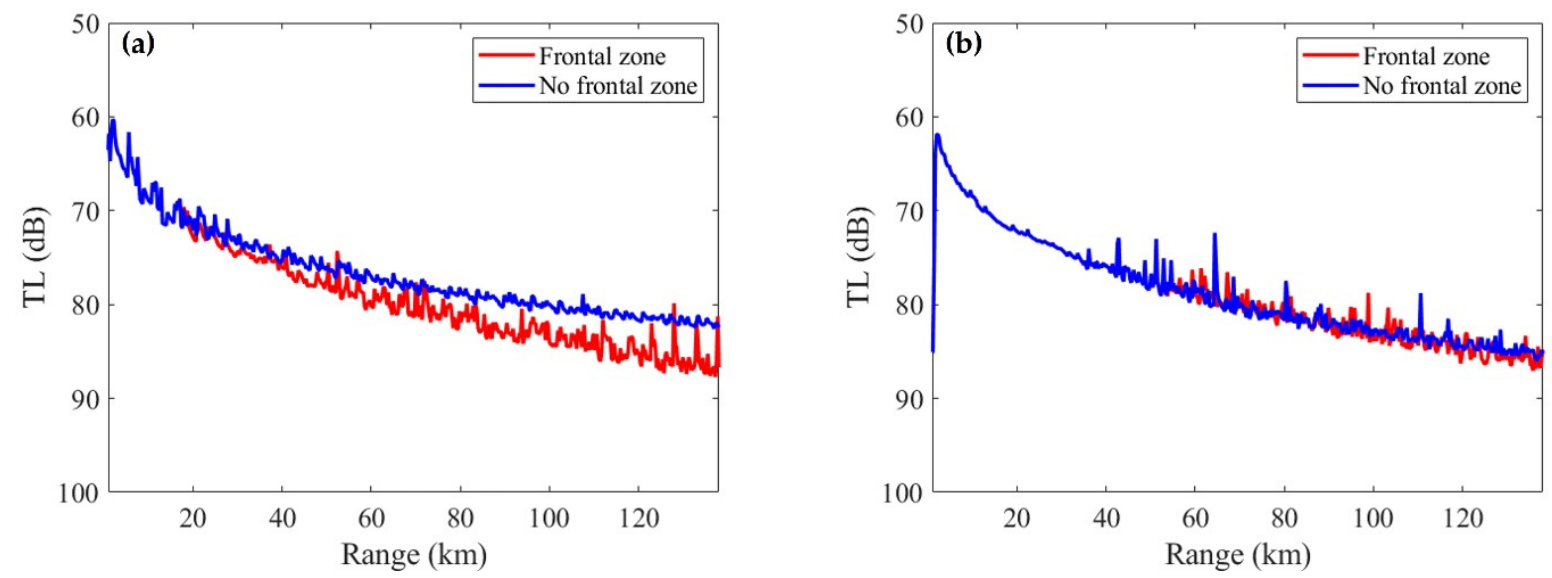

Figure 5. The comparison of the TL between the existing frontal zone and none at different depth range and different directions at the $39.5^{\circ} \mathrm{W}$ section: (a) $0-200 \mathrm{~m}$, the direction is $50.6^{\circ}-51.6^{\circ} \mathrm{N}$; (b) $200-400 \mathrm{~m}$, the direction is $51.6^{\circ}-50.6^{\circ} \mathrm{N}$. The position when the difference exceeds $0.2 \mathrm{~dB}$ is used as the criterion for judging the starting point of the frontal zone, and the above two values are $17.9 \mathrm{~km}$ and $77.2 \mathrm{~km}$, respectively, the errors between the results of the K-means and the calculation of the TL are more than twice the distance between the two sound speed profiles (11.2 km). It is necessary to divide each layer into two layers evenly, respectively, use the K-means algorithm to cluster the SSP, and then verify the accuracy of the new results.

As for the verification of the accuracy of clustering results of the other three layers, we find that all errors are less than the error range given by us $(11.2 \mathrm{~km})$ (the specific error comparison is in Section 3.4).

\subsection{Iterative Layered Processing and Verification}

According to the conclusion of Section 3.3, we need to re-average the stratification of 0-200 $\mathrm{m}$ and 200-400 $\mathrm{m}$, and then use the K-means algorithm to cluster the set of sound speed profiles of these four layers. This is iterative hierarchical processing. We used the K-means algorithm to classify and identify the sound speed profiles of the above four layers and obtained the following clustering results (Figure 6).

Compared with the previous hierarchical clustering results, the results of 0-100 m (Figure 6a) and 0-200 $\mathrm{m}$ (Figure 4a) are similar, but the result of 100-200 $\mathrm{m}$ (Figure 6b) is different, especially in the west of the study sea area, the frontal zone is wider than $0-100 \mathrm{~m}$. The width of the frontal zone at $39^{\circ} 30^{\prime} \mathrm{W}$ section reaches $84.5 \mathrm{~km}$ at 100-200 m, while at 0-100 m, it is $22.4 \mathrm{~km}$. The results of 200-300 m (Figure 6c) and 200-400 m (Figure 4b) are similar, but the result of 300-400 m (Figure 6d) is different. The width of the frontal zone at $39^{\circ} 30^{\prime} \mathrm{W}$ section is $67.2 \mathrm{~km}$ at $300-400 \mathrm{~m}$, which is narrower than $200-300 \mathrm{~m}$.

In order to show the changes of the iterative hierarchical clustering results more intuitively, we plot Figure $4 \mathrm{a}, \mathrm{b}$ and Figure 6 together to get Figure 7 to show the differences of the iterative hierarchical clustering results at different levels. It can be found that the result of $0-200 \mathrm{~m}$ is closer to that of $0-100 \mathrm{~m}$, and the result of $200-400 \mathrm{~m}$ is closer to that of 200-300 m. 

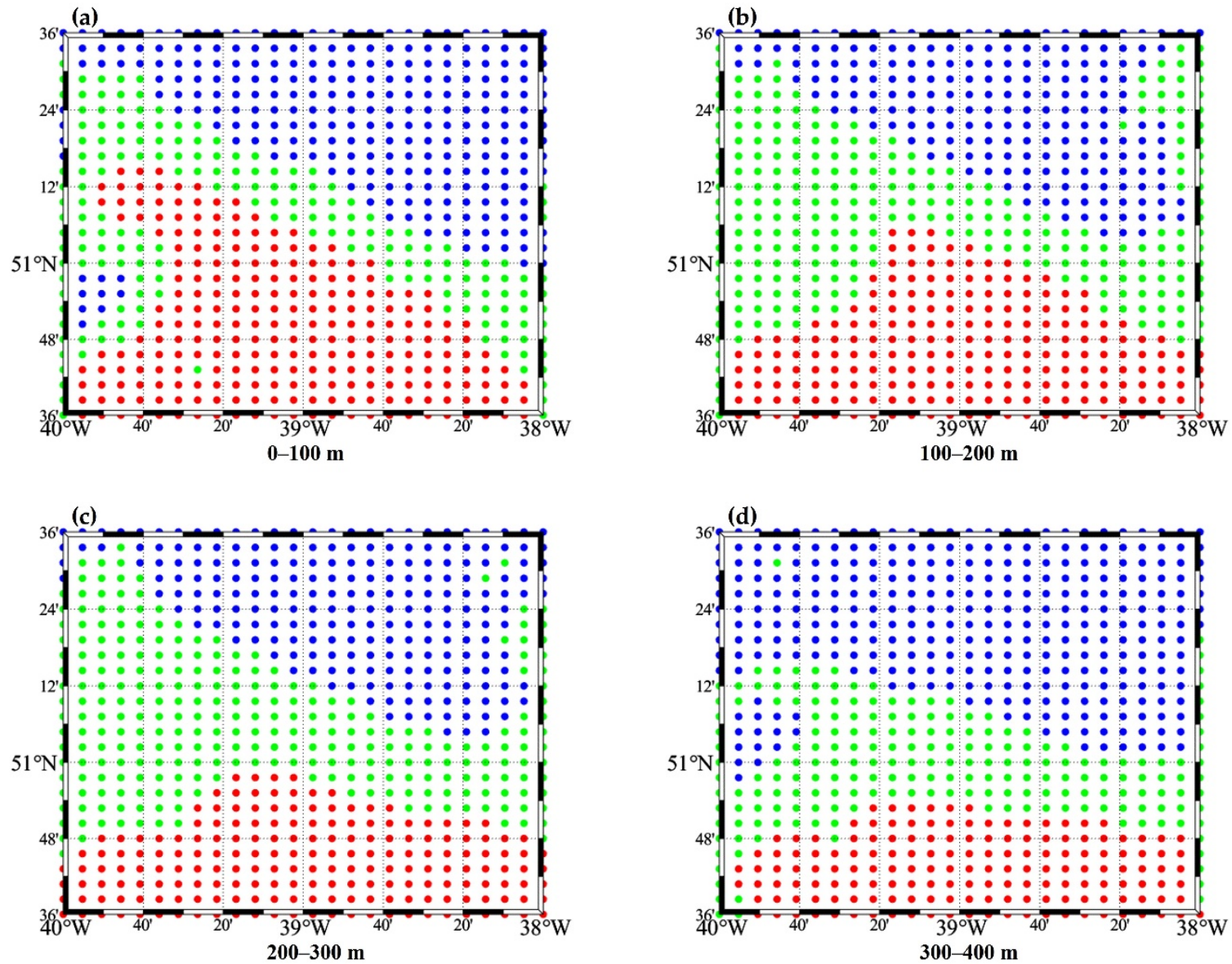

Figure 6. The iterative hierarchical clustering results of sound speed profiles of the study sea area via K-means through re-averaging the stratification of 0-200 $\mathrm{m}$ and 200-400 $\mathrm{m}$ (the blue points represent the north water mass of the frontal zone, the red points represent the south water mass of the frontal zone, and the green points represent the frontal transition water mass): (a) 0-100 m; (b) 100-200 m; (c) 200-300 m; (d) 300-400 m.
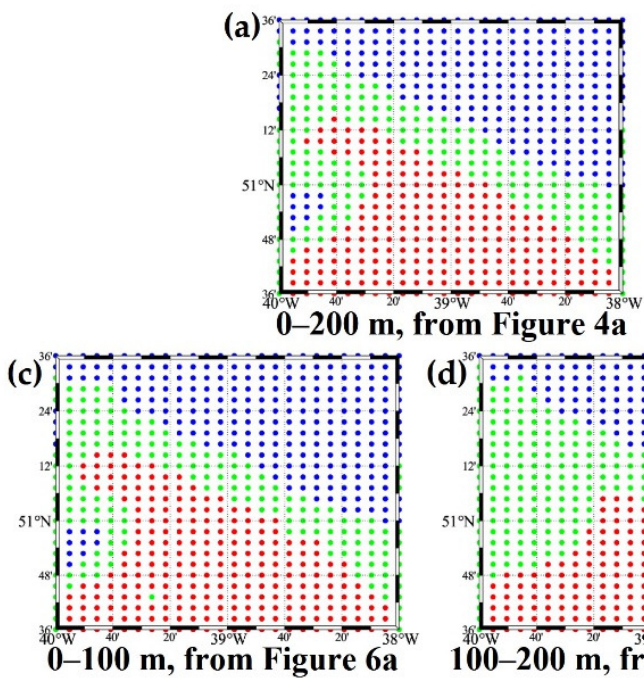

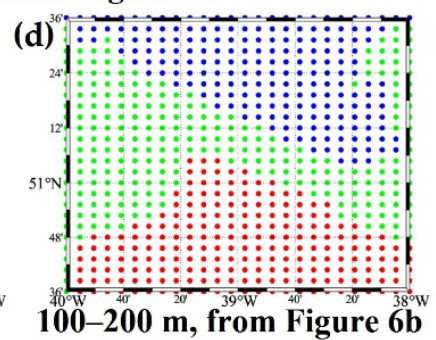

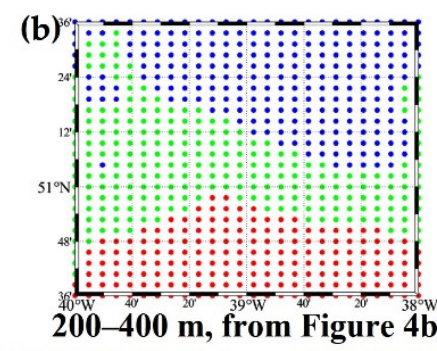
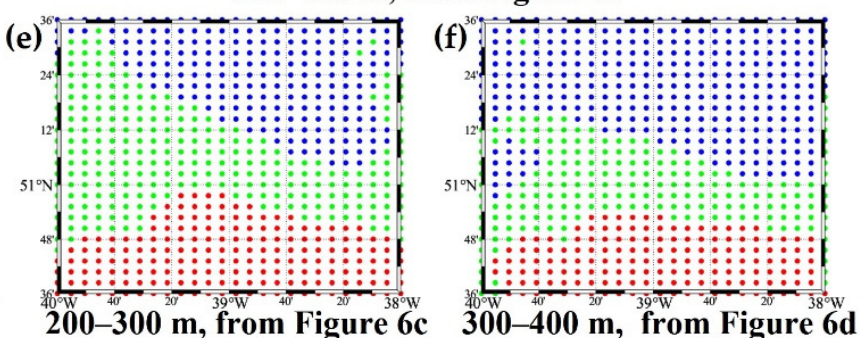

Figure 7. The comparisons of iterative hierarchical clustering results of sound speed profiles via K-means algorithm at 0-400 m. (a,b) are from Figure 4, and (c-f) are from Figure 6. It can be found that the result of 0-200 $\mathrm{m}$ is closer to that of $0-100 \mathrm{~m}$, and the result of $200-400 \mathrm{~m}$ is closer to that of $200-300 \mathrm{~m}$. 
Taking the experiment on $0-100 \mathrm{~m}$ as an example, we selected these three sound speed sections $\left(39.5^{\circ} \mathrm{W}, 39^{\circ} \mathrm{W}\right.$, and $38.5^{\circ} \mathrm{W}$ ) to calculate the $\mathrm{TL}$ (each sound speed section has two directions, so there are six comparisons in Figure 8). The calculation of the TL verifies that the difference between the starting position of the ocean front obtained by the iterative hierarchical clustering result (Figure $6 \mathrm{a}$ ) and the starting position of the frontal zone obtained by the TL calculation is less than twice the distance between the two sound velocity profiles $(11.2 \mathrm{~km})$, which verifies the accuracy of the clustering results under the new stratification.
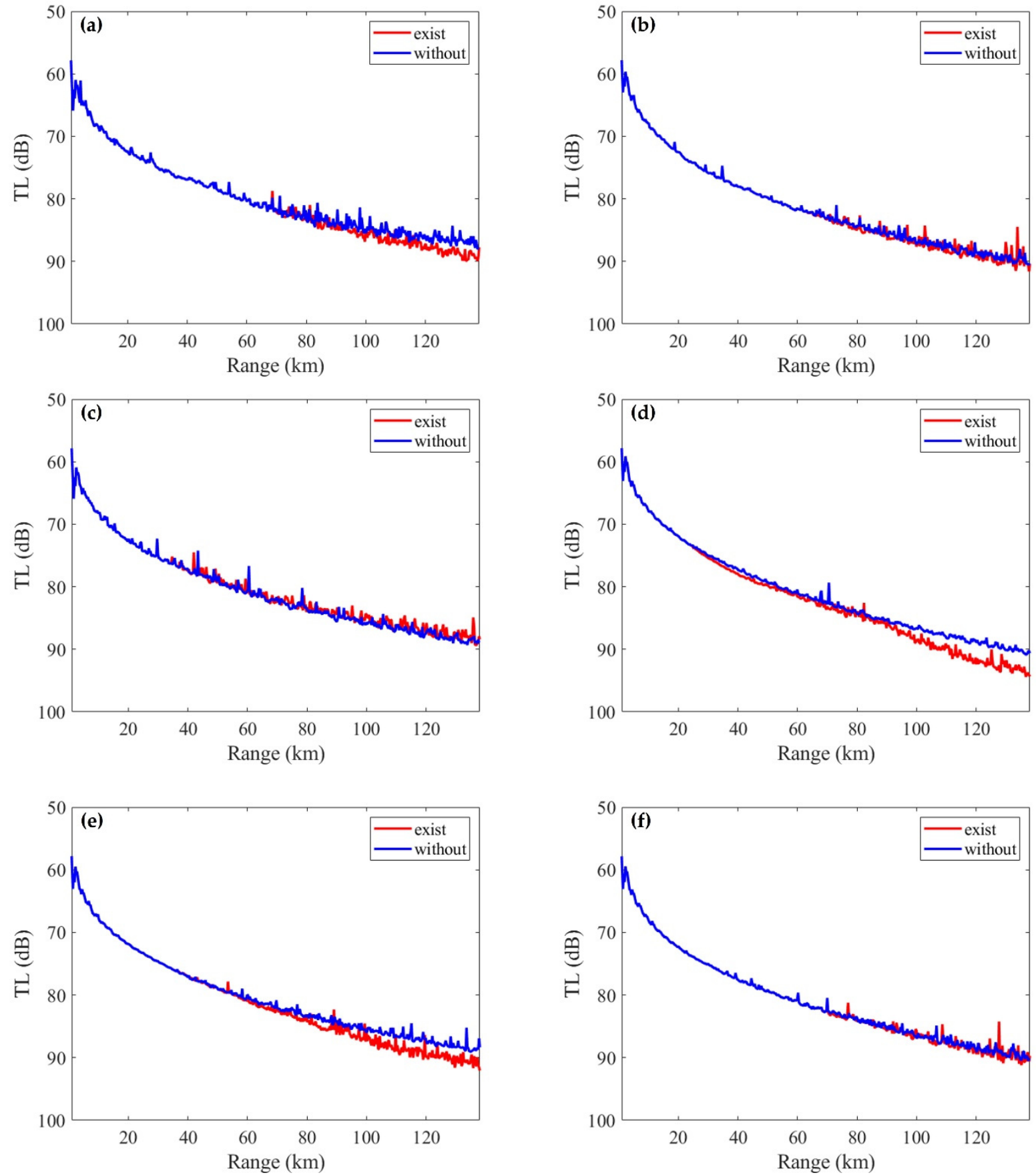

Figure 8. The comparison of the TL between the existing frontal zone and none at different sections and propagation directions (the depth range is $0-100 \mathrm{~m}$ ): (a) $39.5^{\circ} \mathrm{W}$, and the direction is $50.6^{\circ}-51.6^{\circ} \mathrm{N}$; (b) $39^{\circ} \mathrm{W}$, and the direction is $50.6^{\circ}-51.6^{\circ} \mathrm{N}$; (c) $38.5^{\circ} \mathrm{W}$, and the direction is $50.6^{\circ}-51.6^{\circ} \mathrm{N}$; (d) $39.5^{\circ} \mathrm{W}$, and the direction is $51.6^{\circ}-50.6^{\circ} \mathrm{N}$; (e) $39^{\circ} \mathrm{W}$, and the direction is $51.6^{\circ}-50.6^{\circ} \mathrm{N}$; (f) $38.5^{\circ} \mathrm{W}$, and the direction is $51.6^{\circ}-50.6^{\circ} \mathrm{N}$. The iterative hierarchical clustering result (Figure 6a) meets the error standard range for the judgment of the starting point of the frontal zone at 0-100 $\mathrm{m}(11.2 \mathrm{~km})$. 
We gave Tables 1-3 about the comparison of the K-means clustering results of the $39^{\circ} 30^{\prime} \mathrm{W}, 39^{\circ} 00^{\prime} \mathrm{W}$, and $38^{\circ} 30^{\prime} \mathrm{W}$ sections under different conditions with the starting position (SP) of the frontal zone obtained from calculating the TL. We found that the error of all results is less than twice the distance of the adjacent sound speed profiles $(11.2 \mathrm{~km})$. We also calculated the mean error of these three sections, which is $4.3 \mathrm{~km}$. This value is less than the distance between two adjacent sound speed profiles $(5.6 \mathrm{~km})$, which proves that it is feasible to use the K-means algorithm to perform iterative hierarchical clustering of sound speed profiles to detect the frontal zone, and the detecting results are also credible.

Table 1. The comparison of the accuracy of the K-means algorithms on the identification of the frontal zone in different depth ranges at $39^{\circ} 30^{\prime} \mathrm{W}$ section (SP by K-means means the starting point of the frontal zone obtained by K-means, SP by TL means the starting point of the frontal zone obtained by calculating the TL, Error means the difference between SP by K-means and SP by TL).

\begin{tabular}{|c|c|c|c|c|c|}
\hline Sound Speed Section & Depth Range & Propagation Direction & SP by K-Means & SP by TL & Error \\
\hline \multirow{14}{*}{$39^{\circ} 30^{\prime} \mathrm{W}$} & \multirow{2}{*}{$0-100 \mathrm{~m}$} & $50.6^{\circ}-51.6^{\circ} \mathrm{N}$ & $89.6 \mathrm{~km}$ & $85.7 \mathrm{~km}$ & $3.9 \mathrm{~km}$ \\
\hline & & $51.6^{\circ}-50.6^{\circ} \mathrm{N}$ & $33.6 \mathrm{~km}$ & $41.7 \mathrm{~km}$ & $8.1 \mathrm{~km}$ \\
\hline & \multirow[b]{2}{*}{ 100-200 m } & $50.6^{\circ}-51.6^{\circ} \mathrm{N}$ & $39.2 \mathrm{~km}$ & $34.7 \mathrm{~km}$ & $4.5 \mathrm{~km}$ \\
\hline & & $51.6^{\circ}-50.6^{\circ} \mathrm{N}$ & $33.6 \mathrm{~km}$ & $24.1 \mathrm{~km}$ & $9.5 \mathrm{~km}$ \\
\hline & \multirow{2}{*}{$200-300 \mathrm{~m}$} & $50.6^{\circ}-51.6^{\circ} \mathrm{N}$ & $33.6 \mathrm{~km}$ & $39.2 \mathrm{~km}$ & $5.6 \mathrm{~km}$ \\
\hline & & $51.6^{\circ}-50.6^{\circ} \mathrm{N}$ & $33.6 \mathrm{~km}$ & $44.8 \mathrm{~km}$ & $11.2 \mathrm{~km}$ \\
\hline & \multirow{2}{*}{$300-400 \mathrm{~m}$} & $50.6^{\circ}-51.6^{\circ} \mathrm{N}$ & $28.0 \mathrm{~km}$ & $30.5 \mathrm{~km}$ & $2.5 \mathrm{~km}$ \\
\hline & & $51.6^{\circ}-50.6^{\circ} \mathrm{N}$ & $50.4 \mathrm{~km}$ & $54.9 \mathrm{~km}$ & $4.5 \mathrm{~km}$ \\
\hline & \multirow{2}{*}{$400-600 \mathrm{~m}$} & $50.6^{\circ}-51.6^{\circ} \mathrm{N}$ & $44.8 \mathrm{~km}$ & $45.9 \mathrm{~km}$ & $1.1 \mathrm{~km}$ \\
\hline & & $51.6^{\circ}-50.6^{\circ} \mathrm{N}$ & $61.6 \mathrm{~km}$ & $62.4 \mathrm{~km}$ & $0.8 \mathrm{~km}$ \\
\hline & \multirow{2}{*}{$600-800 \mathrm{~m}$} & $50.6^{\circ}-51.6^{\circ} \mathrm{N}$ & $44.8 \mathrm{~km}$ & $47.0 \mathrm{~km}$ & $2.2 \mathrm{~km}$ \\
\hline & & $51.6^{\circ}-50.6^{\circ} \mathrm{N}$ & $67.2 \mathrm{~km}$ & $66.6 \mathrm{~km}$ & $0.6 \mathrm{~km}$ \\
\hline & \multirow{2}{*}{$800-1000 \mathrm{~m}$} & $50.6^{\circ}-51.6^{\circ} \mathrm{N}$ & $61.6 \mathrm{~km}$ & $65.0 \mathrm{~km}$ & $3.4 \mathrm{~km}$ \\
\hline & & $51.6^{\circ}-50.6^{\circ} \mathrm{N}$ & $61.6 \mathrm{~km}$ & $62.7 \mathrm{~km}$ & $1.1 \mathrm{~km}$ \\
\hline
\end{tabular}

Table 2. The comparison of the accuracy of the K-means algorithms on the identification of the frontal zone in different depth ranges at $39^{\circ} 00^{\prime} \mathrm{W}$ section (SP by K-means means the starting point of the frontal zone obtained by K-means, SP by TL means the starting point of the frontal zone obtained by calculating the TL, Error means the difference between SP by K-means and SP by TL).

\begin{tabular}{|c|c|c|c|c|c|}
\hline Sound Speed Section & Depth Range & Propagation Direction & SP by K-Means & SP by TL & Error \\
\hline \multirow{14}{*}{$39^{\circ} 00^{\prime} \mathrm{W}$} & \multirow[b]{2}{*}{ 0-100 m } & $50.6^{\circ}-51.6^{\circ} \mathrm{N}$ & $67.2 \mathrm{~km}$ & $77.3 \mathrm{~km}$ & $10.1 \mathrm{~km}$ \\
\hline & & $51.6^{\circ}-50.6^{\circ} \mathrm{N}$ & $50.4 \mathrm{~km}$ & $53.5 \mathrm{~km}$ & $3.1 \mathrm{~km}$ \\
\hline & \multirow{2}{*}{$100-200 \mathrm{~m}$} & $50.6^{\circ}-51.6^{\circ} \mathrm{N}$ & $67.2 \mathrm{~km}$ & $65.8 \mathrm{~km}$ & $1.4 \mathrm{~km}$ \\
\hline & & $51.6^{\circ}-50.6^{\circ} \mathrm{N}$ & $56.0 \mathrm{~km}$ & $45.4 \mathrm{~km}$ & $10.6 \mathrm{~km}$ \\
\hline & \multirow{2}{*}{$200-300 \mathrm{~m}$} & $50.6^{\circ}-51.6^{\circ} \mathrm{N}$ & $50.4 \mathrm{~km}$ & $47.6 \mathrm{~km}$ & $2.8 \mathrm{~km}$ \\
\hline & & $51.6^{\circ}-50.6^{\circ} \mathrm{N}$ & $56.0 \mathrm{~km}$ & $59.4 \mathrm{~km}$ & $3.4 \mathrm{~km}$ \\
\hline & \multirow{2}{*}{$300-400 \mathrm{~m}$} & $50.6^{\circ}-51.6^{\circ} \mathrm{N}$ & $44.8 \mathrm{~km}$ & $52.1 \mathrm{~km}$ & $7.3 \mathrm{~km}$ \\
\hline & & $51.6^{\circ}-50.6^{\circ} \mathrm{N}$ & $67.2 \mathrm{~km}$ & $66.1 \mathrm{~km}$ & $1.1 \mathrm{~km}$ \\
\hline & \multirow{2}{*}{$400-600 \mathrm{~m}$} & $50.6^{\circ}-51.6^{\circ} \mathrm{N}$ & $61.6 \mathrm{~km}$ & $61.3 \mathrm{~km}$ & $0.3 \mathrm{~km}$ \\
\hline & & $51.6^{\circ}-50.6^{\circ} \mathrm{N}$ & $72.8 \mathrm{~km}$ & $68.3 \mathrm{~km}$ & $4.5 \mathrm{~km}$ \\
\hline & \multirow{2}{*}{$600-800 \mathrm{~m}$} & $50.6^{\circ}-51.6^{\circ} \mathrm{N}$ & $61.6 \mathrm{~km}$ & $66.6 \mathrm{~km}$ & $5.0 \mathrm{~km}$ \\
\hline & & $51.6^{\circ}-50.6^{\circ} \mathrm{N}$ & $72.8 \mathrm{~km}$ & $82.0 \mathrm{~km}$ & $9.2 \mathrm{~km}$ \\
\hline & \multirow{2}{*}{$800-1000 \mathrm{~m}$} & $50.6^{\circ}-51.6^{\circ} \mathrm{N}$ & $56.0 \mathrm{~km}$ & $60.2 \mathrm{~km}$ & $4.2 \mathrm{~km}$ \\
\hline & & $51.6^{\circ}-50.6^{\circ} \mathrm{N}$ & $78.4 \mathrm{~km}$ & $79.8 \mathrm{~km}$ & $1.4 \mathrm{~km}$ \\
\hline
\end{tabular}


Table 3. The comparison of the accuracy of the K-means algorithms on the identification of the frontal zone in different depth ranges at $38^{\circ} 30^{\prime} \mathrm{W}$ section (SP by K-means means the starting point of the frontal zone obtained by K-means, SP by TL means the starting point of the frontal zone obtained by calculating the TL, Error means the difference between SP by K-means and SP by TL).

\begin{tabular}{|c|c|c|c|c|c|}
\hline Sound Speed Section & Depth Range & Propagation Direction & SP by K-Means & SP by TL & Error \\
\hline \multirow{14}{*}{$38^{\circ} 30^{\prime} \mathrm{W}$} & \multirow{2}{*}{$0-100 \mathrm{~m}$} & $50.6^{\circ}-51.6^{\circ} \mathrm{N}$ & $50.4 \mathrm{~km}$ & $42.0 \mathrm{~km}$ & $8.4 \mathrm{~km}$ \\
\hline & & $51.6^{\circ}-50.6^{\circ} \mathrm{N}$ & $78.4 \mathrm{~km}$ & $77.0 \mathrm{~km}$ & $1.4 \mathrm{~km}$ \\
\hline & \multirow[b]{2}{*}{$100-200 \mathrm{~m}$} & $50.6^{\circ}-51.6^{\circ} \mathrm{N}$ & $50.4 \mathrm{~km}$ & $52.3 \mathrm{~km}$ & $1.9 \mathrm{~km}$ \\
\hline & & $51.6^{\circ}-50.6^{\circ} \mathrm{N}$ & $72.8 \mathrm{~km}$ & $68.3 \mathrm{~km}$ & $4.5 \mathrm{~km}$ \\
\hline & \multirow{2}{*}{$200-300 \mathrm{~m}$} & $50.6^{\circ}-51.6^{\circ} \mathrm{N}$ & $39.2 \mathrm{~km}$ & $36.7 \mathrm{~km}$ & $2.5 \mathrm{~km}$ \\
\hline & & $51.6^{\circ}-50.6^{\circ} \mathrm{N}$ & $72.8 \mathrm{~km}$ & $82.9 \mathrm{~km}$ & $10.1 \mathrm{~km}$ \\
\hline & \multirow{2}{*}{$300-400 \mathrm{~m}$} & $50.6^{\circ}-51.6^{\circ} \mathrm{N}$ & $44.8 \mathrm{~km}$ & $50.4 \mathrm{~km}$ & $5.6 \mathrm{~km}$ \\
\hline & & $51.6^{\circ}-50.6^{\circ} \mathrm{N}$ & $84.0 \mathrm{~km}$ & $80.4 \mathrm{~km}$ & $3.6 \mathrm{~km}$ \\
\hline & \multirow{2}{*}{$400-600 \mathrm{~m}$} & $50.6^{\circ}-51.6^{\circ} \mathrm{N}$ & $39.2 \mathrm{~km}$ & $38.6 \mathrm{~km}$ & $0.6 \mathrm{~km}$ \\
\hline & & $51.6^{\circ}-50.6^{\circ} \mathrm{N}$ & $84.0 \mathrm{~km}$ & $80.6 \mathrm{~km}$ & $3.4 \mathrm{~km}$ \\
\hline & \multirow{2}{*}{$600-800 \mathrm{~m}$} & $50.6^{\circ}-51.6^{\circ} \mathrm{N}$ & $28.0 \mathrm{~km}$ & $30.5 \mathrm{~km}$ & $2.5 \mathrm{~km}$ \\
\hline & & $51.6^{\circ}-50.6^{\circ} \mathrm{N}$ & $84.0 \mathrm{~km}$ & $86.0 \mathrm{~km}$ & $2.0 \mathrm{~km}$ \\
\hline & \multirow{2}{*}{$800-1000 \mathrm{~m}$} & $50.6^{\circ}-51.6^{\circ} \mathrm{N}$ & $39.2 \mathrm{~km}$ & $40.9 \mathrm{~km}$ & $1.7 \mathrm{~km}$ \\
\hline & & $51.6^{\circ}-50.6^{\circ} \mathrm{N}$ & $78.4 \mathrm{~km}$ & $87.9 \mathrm{~km}$ & $9.5 \mathrm{~km}$ \\
\hline
\end{tabular}

\subsection{The Construction of the Three-Dimensional Geometric Structure of the GSF}

After verifying the accuracy of clustering results based on the calculation of the TL, we used the results of iterative hierarchical clustering of sound speed profiles via the K-means algorithm to reconstruct the three-dimensional geometric structure of the GSF. The reconstruction method is to use the frontal zone identified by the K-means algorithm hierarchical iterative clustering SSP as the structure of the GSF at this layer. Finally, we got the structure of the GSF in Figure 9. We can see that the final structure of the GSF is divided into seven layers in the depth direction, including 0-100 m, 100-200 m, 200-300 m, $300-400 \mathrm{~m}, 400-600 \mathrm{~m}, 600-800 \mathrm{~m}$, and $800-1000 \mathrm{~m}$.
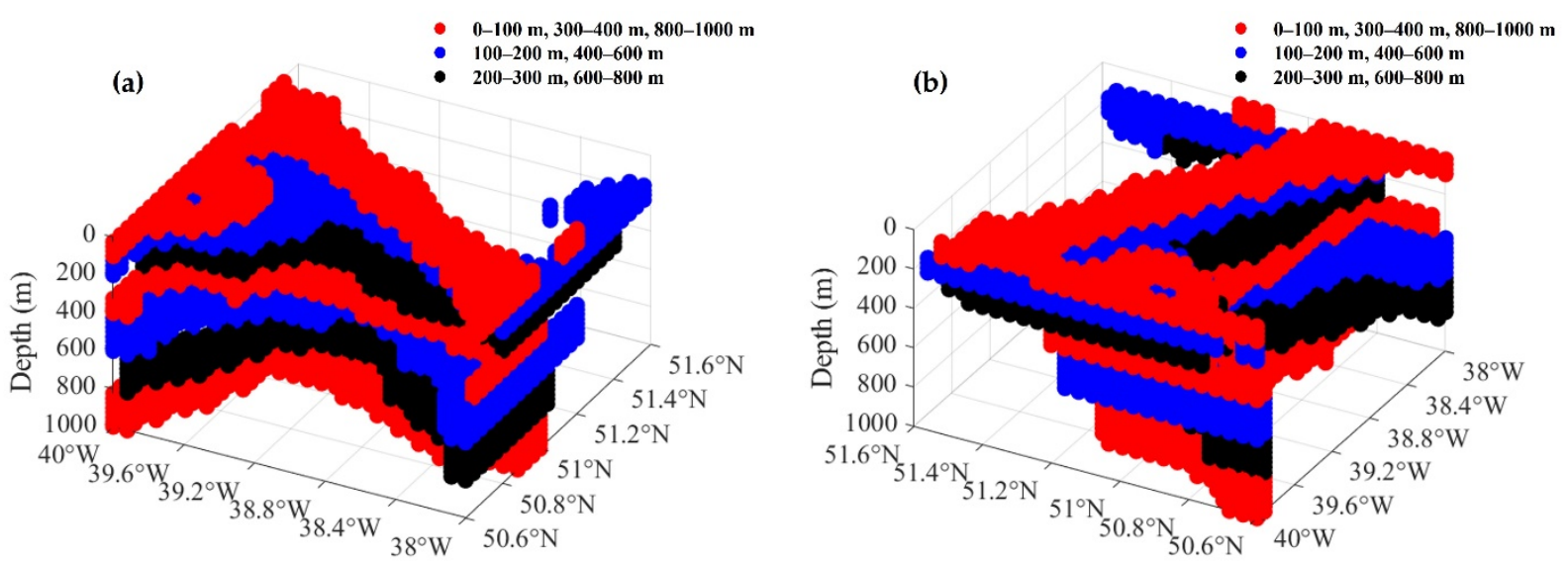

Figure 9. The three-dimensional geometric structure of the GSF obtained by iterative hierarchical clustering of sound speed profiles based on K-means algorithm: (a) angle 1; (b) angle 2. The influence depth of the GSF is 0-1000 m. Finally, it is divided into seven layers. Different color regions represent the results in different layers.

Notably, the previous studies all used SSP of the full sea deep for clustering [14], but we used the characteristics of GSF in different layers to classify the research sea area into five layers as our initial stratification. Moreover, in our study, there is a key step of iterative optimization and stratification based on the accuracy of the K-means clustering results. Finally, the study area is divided into seven layers in the depth direction and the results of 
iterative hierarchical clustering can meet the allowable range of the error. The results of iterative hierarchical clustering of sound speed profiles can realize the reconstruction of the GSF.

We proposed a new method to detect the frontal zone in this paper, which is from the perspective of ocean acoustics and then we analyzed the sound speed profile by K-means, got the results, and verified them with the calculation results of TL, to complete iterative layering and reconstruct the GSF. Only as far as the proposed method itself is concerned, it is reliable, because the clustering analysis algorithm we used in the research process is mature in theory, and it is reasonable to judge the starting position of the frontal zone by calculating the TL, so as to verify the accuracy of the results obtained by the K-means algorithm. The whole research process is a closed-loop. There is a key step of iterative optimization and stratification based on the accuracy of the K-means clustering results, which is the main innovation of this paper. Iterative hierarchical clustering SSP by K-means algorithm provides a new method for judging the frontal zone and reconstructing the geometric model of ocean front in different depth ranges.

\section{Conclusions}

In this paper, we use the K-means algorithm to perform iterative hierarchical clustering of the sound speed profiles of the Gulf Stream related study area and construct the geometric structure of the GSF based on the clustering results for the first time. We use the characteristics of GSF in different layers to classify the research sea area into five layers as initial stratification. Meanwhile, considering that acoustic ray tracing is a very sensitive tool for detecting the location of ocean fronts because of the strong dependence of the TL on SSP structure, we verify the accuracy of the clustering results in different depth ranges by using the acoustic ray tracing to calculate the TL. However, by calculating the TL and obtaining the SP of the frontal zone, it is found that the SPs by K-means exceed the error range for the 0-200 $\mathrm{m}$ and $200-400 \mathrm{~m}$ layers, while the SPs by K-means are within the error range for the other three layers of $400-1000 \mathrm{~m}$. Therefore, we divide the above two layers with larger errors (0-200 m and 200-400 m) evenly and complete the clustering and verification process again. This is an iterative and optimization process, and it is also one of the main innovations of this paper. The result of the iterative hierarchical clustering is that the depth range of the GSF is divided into seven layers (0-100 m, 100-200 m, 200-300 m, $300-400 \mathrm{~m}, 400-600 \mathrm{~m}, 600-800 \mathrm{~m}$ and $800-1000 \mathrm{~m}$ ). The clustering result of each layer is within the error range of the SP of the frontal zone obtained by the calculation of the TL. Finally, we successfully construct the three-dimensional structure of the GSF for the first time. Iterative hierarchical clustering SSP by K-means algorithm provides a new method for judging the frontal zone and reconstructing the geometric model of ocean front in different depth ranges.

The ocean front is one of the most important phenomena in ocean dynamics, for its detection, the traditional method is from the perspective of oceanography, such as the method of the temperature gradient. However, for ocean acoustic detection, this detection method based on temperature gradient is not straightforward, because the basis and core of acoustic detection is the SSP. For this reason, the identification of the SSP through the K-means algorithm can provide a new insight from the perspective of ocean acoustics into the judgment of ocean fronts in different layers. Compared with the previous research, we can further control the error of the clustering analysis results to an acceptable range through the key step of iterative optimization of stratification, and the GSF structure obtained by this approach also appears more detailed in the depth direction.

It should be pointed out that although we have proved the applicability of this method to the GSF in this paper, we have not proved whether this method is applicable in other mesoscale phenomena in the ocean, which is also one of the key points of future research. In addition, we will also explore the feasibility of this method for spatial structure modeling in other fields. 
Author Contributions: Conceptualization, W.C. (Wei Chen), Y.L. and L.M.; methodology, Y.L. and W.C. (Wen Chen); software, Y.C.; validation, Y.L.; formal analysis, Y.C. and Z.M.; investigation, W.C. (Wen Chen) and Y.L.; writing—original draft preparation, Y.L. and W.C. (Wei Chen); writing—review and editing, W.C. (Wei Chen) and L.M.; funding acquisition, Y.C. All authors have read and agreed to the published version of the manuscript.

Funding: This research was funded by the National Natural Science Foundation of China under contract No. 61901488.

Institutional Review Board Statement: Not applicable.

Informed Consent Statement: Not applicable.

Data Availability Statement: Not applicable.

Conflicts of Interest: The authors declare no conflict of interest.

\section{References}

1. Belkin, I.M.; Cornillon, P.C.; Sherman, K. Fronts in large marine ecosystems. Prog. Oceanogr. 2009, 81, 223-236. [CrossRef]

2. Bost, C.A.; Cotté, C.; Bailleul, F.; Cherel, Y.; Charrassin, J.B.; Guinet, C. The importance of oceanographic fronts to marine birds and mammals of the southern oceans. J. Mar. Syst. 2009, 78, 363-376. [CrossRef]

3. Peter, C.; Wang, G. Seasonal variability of thermohaline front in the central South China Sea. J. Oceanogr. 2003, 59, 65-78. [CrossRef]

4. Avijit, G.; Allan, R. Feature-oriented regional modeling of oceanic fronts. Dyn. Atmos. Ocean. 2002, 36, 201-232. [CrossRef]

5. Moore, J.K.; Abbott, M.R.; Richman, J.G. Variability in the location of the Antarctic Polar Front $\left(90^{\circ}-20^{\circ} \mathrm{W}\right)$ from satellite sea surface temperature data. J. Geophys. Res. Ocean. 1997, 102, 27825-27833. [CrossRef]

6. Chen, B.; Liang, M.A.; Zhang, C.; Bing, L.I.; Liu, H. Ocean front analysis in subdivided sea areas by using satellite remote sea surface temperature data. Ocean. Eng. 2018, 36, 108-118.

7. Eberhardt, W.B.; Hashimoto, E.J.; Davis, A.; Anderson, A.L. Effect of ocean frontal extent on sound transmission. J. Acoust. Soc. Amer. 1978, 64, S75. [CrossRef]

8. Jian, Y.; Zhang, J.; Jia, Y. A sound speed computation model in oceanic front area and its application in studying the effect on sound propagation. Adv. Mar. Sci. 2006, 24, 166-172.

9. Wang, X.; Khazaie, S.; Chen, X. Linear approximation of underwater sound speed profile: Precision analysis in direct and inverse problems. Appl. Acoust. 2018, 140, 63-73. [CrossRef]

10. Liu, J.; Zhang, Y.; Zhang, X. Characteristics of the spatiotemporal variation of the Tsushima current front and a preliminary analysis on the nearby sound field. J. Appl. Oceanogr. 2015, 34, 476-483.

11. Mandelberg, M.D.; Frizzell-Makowski, L.J. Acoustic provincing of ocean basins. In Proceedings of the Oceans 2000 MTS/IEEE Conference and Exhibition, Providence, RI, USA, 11-14 September 2000; pp. 105-108. [CrossRef]

12. Abiva, J.; Fabbri, T.; Vicen-Bueno, R. Automatic classification of sound speed profiles using PCA and self-organizing map techniques. In Proceedings of the Oceans Marseille, Marseille, France, 17-20 June 2019; pp. 1-10. [CrossRef]

13. Dubberley, J.; Zingerelli, R. Fuzzy clustering of oceanographic sound speed profiles for acoustic characterization. J. Acoust. Soc. Am. 2008, 123, 8665-8669. [CrossRef]

14. Chen, C.; Yang, K.; Duan, R.; Ma, Y.L. Acoustic propagation analysis with a sound speed feature model in the front area of Kuroshio Extension. Appl. Ocean Res. 2017, 68, 1-10. [CrossRef]

15. Liu, Y.; Chen, W.; Chen, W.; Chen, Y.; Ma, L.; Meng, Z. Reconstruction of ocean front model based on sound speed clustering and its effectiveness in ocean acoustic forecasting. Appl. Sci. 2021, 11, 8461. [CrossRef]

16. Liu, Y.; Chen, W.; Chen, W.; Chen, Y.; Ma, L.; Meng, Z. Reconstruction method of ocean front model based on fuzzy cluster analysis of sound speed profile. IEEE Access 2021, 9, 112714-112725. [CrossRef]

17. Leterme, S.C.; Pingree, R.D. The Gulf Stream, rings and North Atlantic eddy structures from remote sensing (Altimeter and SeaWiFS). J. Mar. Syst. 2008, 69, 77-190. [CrossRef]

18. Lambert, R.B., Jr. Lateral mixing processes in the Gulf stream. J. Phys. Oceanogr. 1982, 12, 851-861. [CrossRef]

19. Chassignet, E.P.; Hulburt, H.E.; Smedstad, O.M.; Halliwell, G.R.; Hogan, P.J. The HYCOM (HYbrid Coordinate Ocean Model) data assimilative system. J. Mar. Syst. 2007, 65, 60-83. [CrossRef]

20. Chassignet, E.P.; Smith, L.T.; Halliwell, G.R.; Bleck, R. North Atlantic simulations with the Hybrid Coordinate Ocean Model (HYCOM): Impact of the vertical coordinate choice, reference pressure, and thermobaricity. J. Phys. Oceanogr. 2003, 33, 2504-2526. [CrossRef]

21. Wilson Wayne, D. Equation for the speed of sound in sea water. J. Acoust. Soc. Am. 1960, 32, 1357. [CrossRef]

22. Rajkumar, K.V.; Yes babu, A.U.; Subrahmanyam, K. Fuzzy clustering and Fuzzy C-Means partition cluster analysis and validation studies on a subset of citescore dataset. Int. J. Electr. Comput. Eng. 2019, 9, 2760-2770. [CrossRef]

23. Qi, H.; Li, J.; Di, X.; Ren, W.; Zhang, F. Improved K-means clustering algorithm and its applications. Recent Pat. Eng. 2018, 13, 403-409. [CrossRef] 
24. Gul, S.; Zaidi, S.; Khan, R.; Wala, A.B. Underwater acoustic channel modeling using BELLHOP ray tracing method. In Proceedings of the 2017 14th International Bhurban Conference on Applied Sciences and Technology (IBCAST), Islamabad, Pakistan, 10-14 January 2017; pp. 665-670. [CrossRef]

25. White, B.S.; Norris, A.; Bayliss, A.; Burridge, R. Some remarks on the Gaussian beam summation method. Geophys. J. R. Astron. Soc. 1987, 89, 579-636. [CrossRef]

26. Boden, L. Time domain analysis of normal mode, parabolic, and ray solutions of the wave equation. J. Acoust. Soc. Am. 1991, 90, 954-958. [CrossRef]

27. Shapiro, G.; Chen, F.; Thain, R. The effect of ocean fronts on acoustic wave propagation in the Celtic Sea. J. Mar. Syst. 2014, 139, 217-226. [CrossRef]

28. Weinberg, N.L.; Clark, J.G. Horizontal acoustic refraction through ocean mesoscale eddies and fronts. J. Acoust. Soc. Am. 1980, 68, 703-705. [CrossRef] 